\title{
La trata de personas con fines de explotación sexual y prositiución
}

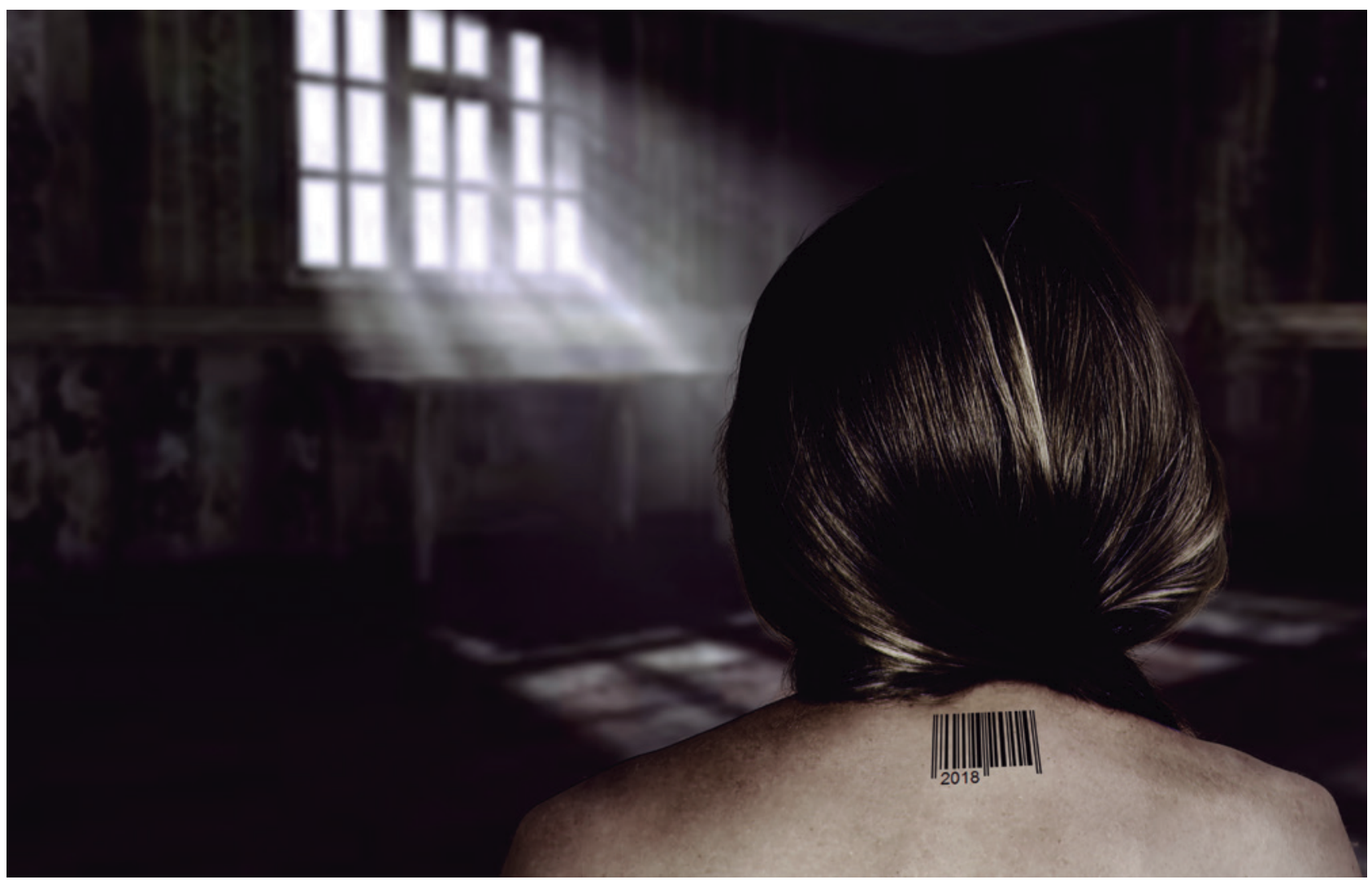

En el presente artículo se realiza una distinción

entre diferentes conceptos que se relacionan con

la trata, el tráfico de personas con fines de

explotación sexual y los tipos de prostitución. Se

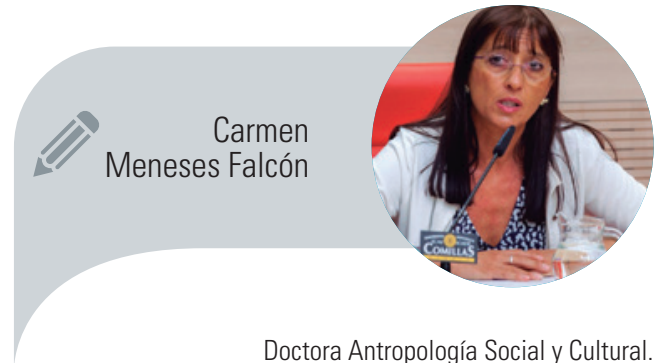

Universidad Pontificia Comillas cmeneses@comillas.edu

describen algunos aspectos del desarrollo de la

prostitución para centrarse en la demanda de

servicios sexuales y el papel de los varones en ella.

Se ofrecen algunas sugerencias educativas en 


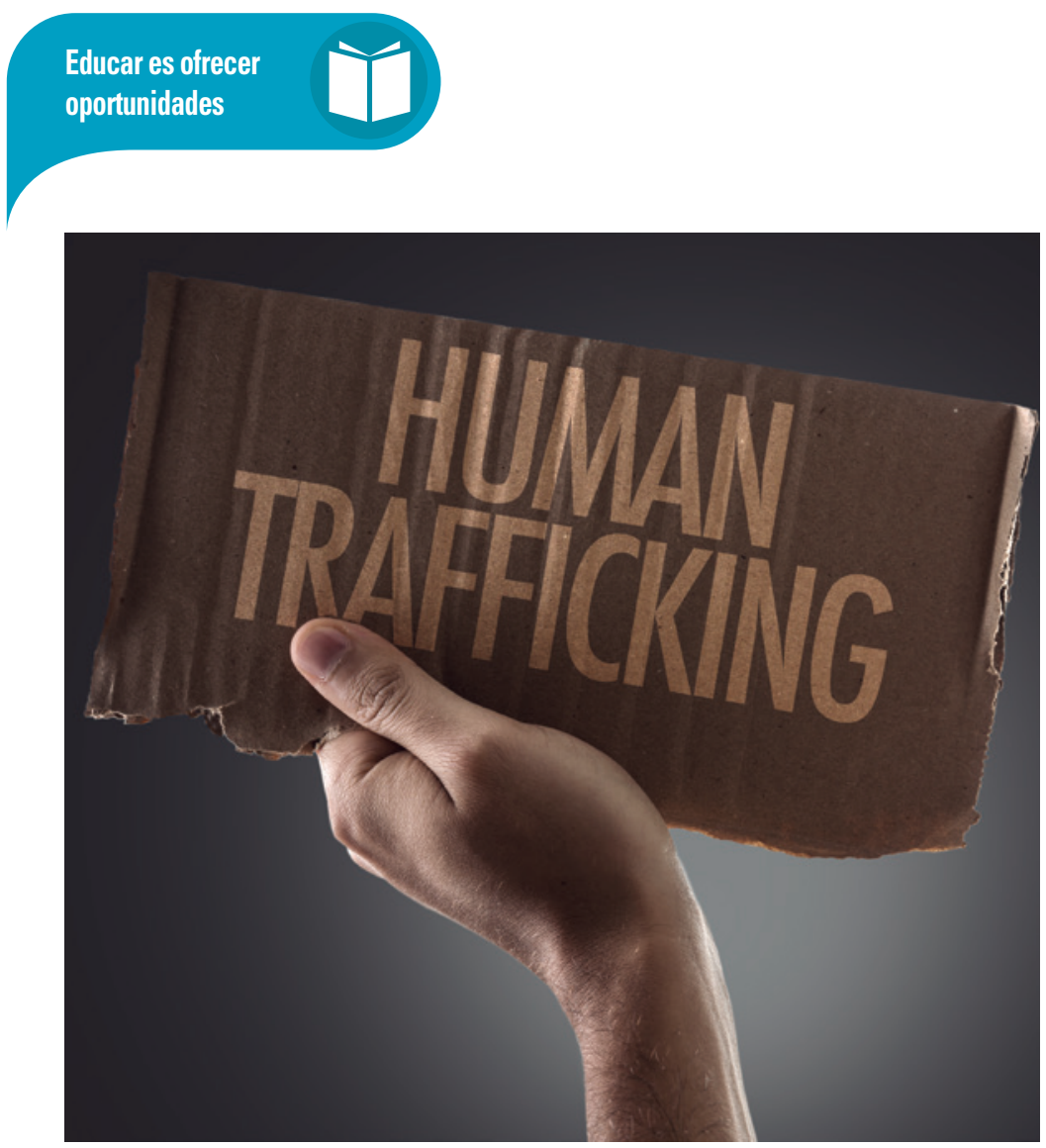

Con cierta asiduidad nos encontramos algunas noticias en los medios de comunicación sobre mujeres que están siendo explotadas en los clubs de alterne, o que son víctimas de trata y se ha desarticulado una red de tratantes que abusaba de ellas. También en algún momento nos hemos encontrado algún flyer o folleto, anunciando servicios sexuales en el coche o tirado en la calle. Alguna noticia en el periódico ${ }^{1}$ ha señalado que en ocasiones los menores aprovechan para recogerlos, ojearlos o coleccionarlos entre ellos. ¿Qué hay detrás de todo esto? ¿Cómo actuar ante nuestros hijos cuando nos encontramos que entre sus cosas hay algún flyer de servicios sexuales?

Las noticias en ocasiones no distinguen los conceptos ni los fenómenos sociales, que se agrupan todos como si fuesen iguales. La trata es una consecuencia de la prostitución, pero no todas las personas que se prostituyen son víctimas de trata. Por otra parte, la coacción a la prostitución y la explotación sexual son aspectos que se pueden sumar a lo anterior o producirse al margen. Por último, se habla indistintamente de trata y de tráfico de mujeres y niñas con fines de

1 La Vanguardia, 11 mayo 2017 http://www.lavanguardia.com/local/madrid/20170511/422466106482/ madrid-harta-publicidad-prostitucion-parabrisasoches-multas.html explotación sexual como si fuera lo mismo y tampoco lo es. Vamos a definir estos conceptos.

\section{La trata y el tráfico de personas: dos situaciones distintas}

La trata de personas es un delito muy grave contra las personas, que puede tener distintas finalidades: la explotación sexual, que es la más numerosa e implica generalmente a niños, niñas y mujeres; la de explotación laboral con una mayor presencia de hombres; la que tiene como finalidad la venta de órganos, con poca incidencia en España, y la destinada a matrimonios forzados, principalmente de niñas y mujeres. La trata es considerada la esclavitud del siglo XXI, porque supone la violación de todos los derechos humanos y la ejecución de la violencia contra las personas, especialmente contra las mujeres, que no pueden salir de esa situación si no son rescatadas o tienen la suerte de escapar. La trata se produce cuando una persona es captada en su país de origen, engañándola con falsas promesas de empleo o situación de bienestar en otro país, es trasladada y cuando llega al país de destino, las promesas son falsas y es obligada a realizar una ocupación o actividad contra su voluntad, para la que se utilizarán coacciones, amenazas o violencia hasta que se doblega a esa persona; y todo el dinero que se obtenga por la actividad que desarrolle (laboral, sexual, etc.) será para sus tratantes². La trata es diferente al tráfico de personas. En este último caso el delito no es contra las personas sino contra el Estado, porque se incumplen los tratados de tránsito internacional de frontera de cada país, al entrar ilegalmente en un estado. De hecho, el delito de trata es mucho más grave y más castigado en el Código Penal que el

2 Véase el Protocolo de Palermo, del año 2000 donde queda recogido y es firmado por la gran mayoría de países europeos, entre ellos España. El delito de trata queda recogido en el Código Penal español en la modificación del mismo en el año 2010 


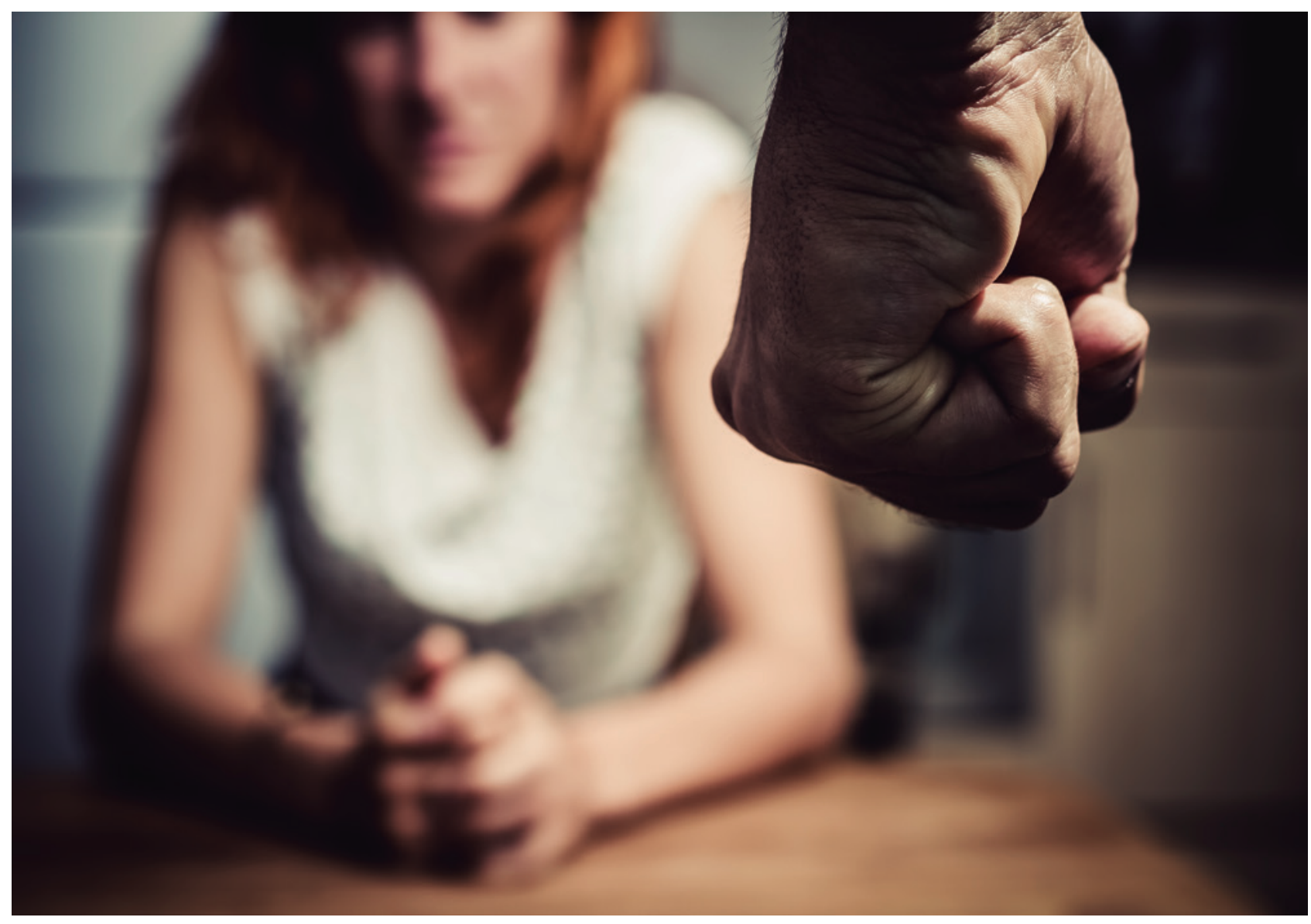

delito de tráfico, que es más leve. El tráfico solo se refiere al traslado de fronteras. Una persona puede ser ayudada por una red de traficantes que le facilita la entrada ilegal en un país europeo, como España, y su implicación solo será eso, el traslado. Generalmente las personas traficadas voluntariamente son trasladadas a otro país para mejorar sus condiciones de vida y pagan a la red por ello. Las redes de tratantes y traficantes son distintas, aunque ambas tengan una finalidad lucrativa: ganar dinero.

\section{Coacción a la prostitución y explotación sexual}

Otros delitos diferentes, pero que se pueden unir a estos dos, son la coacción para ejercer la prostitución y la explotación sexual. La coacción o inducción a la prostitución también está castigada en el Código Penal, siendo muy grave cuando se trata de menores de edad. Una mujer - una niña pueden ser traídas a España -ya sean engañadas o no- con otra finalidad que la prostitución y posteriormente ser inducidas y coaccionadas para que la ejerzan. Pero también esa inducción o coacción a la prostitución puede darse en niñas, adolescentes y mujeres jóvenes españolas por parte de proxenetas o redes de prostitución en España pues, aunque son minoritarias, existen. Por último, otro concepto y hecho que puede producirse es el de explotación sexual, ya esté la persona explotada ejerciendo la prostitución voluntariamente o ejerciéndola contra su voluntad.

La prostitución voluntaria, coactiva y la trata con fines de explotación sexual se confunden y se toman como sinónimos, siendo situaciones diferentes, aunque las personas, niñas y mujeres, puedan pasar por las tres circunstancias. Una joven latinoamericana puede venir a España a trabajar como camarera, pero al no encontrar trabajo, una amiga puede decirle que la prostitución es una salida para ganar dinero rápido. Dependiendo cómo ejerza la prostitución podrá ser explotada sexualmente o no. Mientras que el concepto de explotación laboral está claro porque es más fácil de determinar, dado que existe una legislación laboral que permite hacerlo, no pasa lo mismo con la explotación sexual, que al no es- 


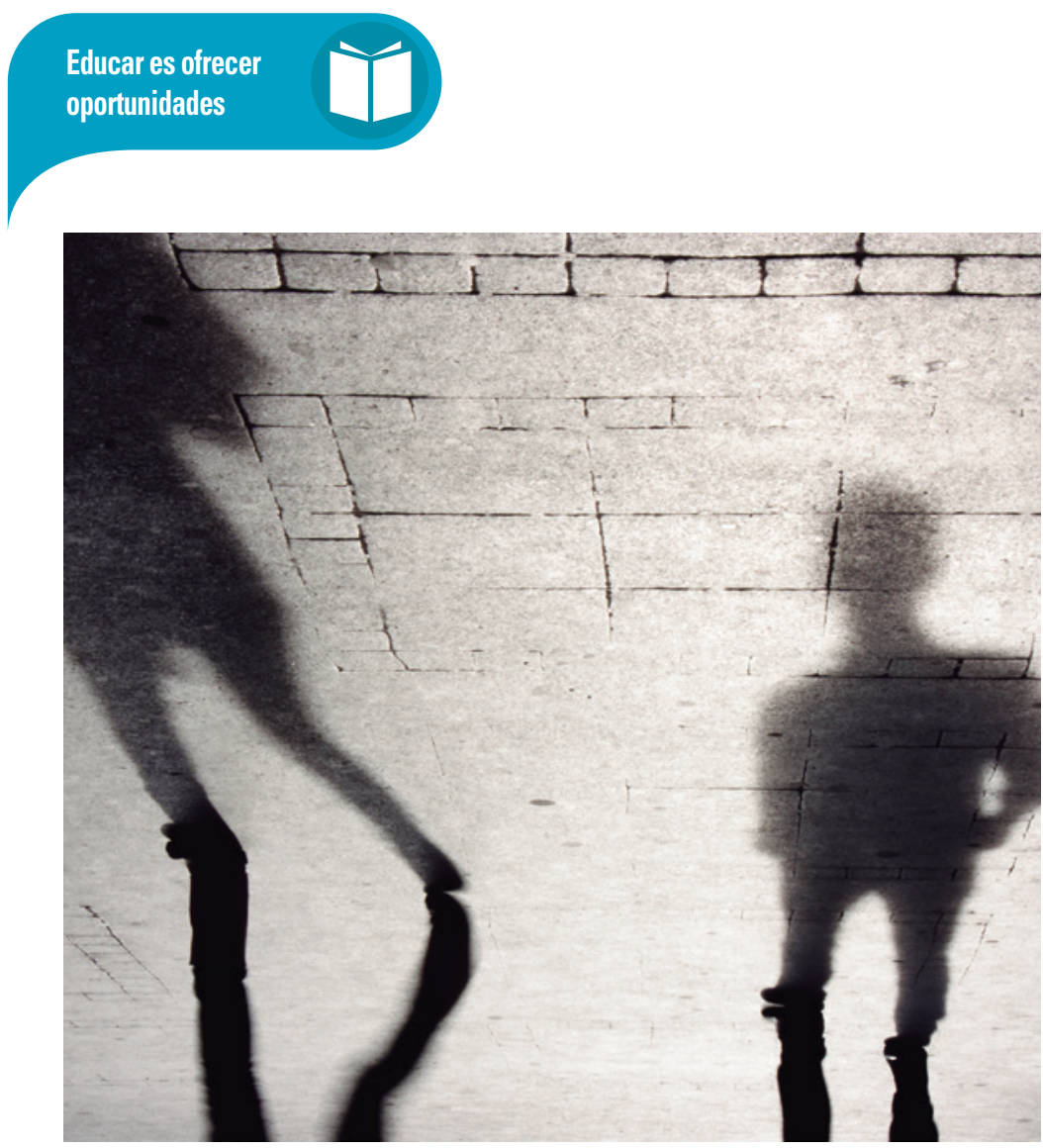

tar regulada no se pueden establecer los criterios. No obstante, la posibilidad de regular la prostitución en España requiere un debate serio para no caer en los problemas y errores que han tenido otros países que tomaron esta decisión. La prostitución en España es alegal, no está ni prohibida ni regulada, por tanto, resulta muy complicado para el poder ejecutivo y judicial valorar cuándo una joven ha sido explotada. Solo tenemos que ver las sentencias judiciales y podremos apreciarlo. Pero una cosa es clara, cuando el dinero que percibe de la prostitución no es para la persona que se prostituye puede existir proxenetismo y explotación, la línea es muy fina a veces y de difícil valoración.

\section{Conexiones entre prostitución y trata con fines de explotación sexual}

La prostitución es una actividad muy lucrativa en la que podemos distinguir distintos protagonistas: las personas que ejercen la prostitución, las personas que compran servicios sexuales y las personas que trabajan, se lucran o se ocupan en el sector o industria del sexo, ya sea legal o ilegalmente. En España podríamos distinguir tres o cuatro contextos de oferta de servicios sexuales. En primer lugar, los clubs urbanos o de carretera, que son locales de alterne y oferta de servicios se- xuales; en segundo lugar, los pisos o apartamentos, que suelen anunciarse mediante anuncios; en tercer lugar, algunas casas de masajes, que además de esta oferta ofrecen también servicios sexuales; y por último la oferta callejera, en el centro de las ciudades o los polígonos industriales. En todos estos sectores podemos hallar mujeres que ejercen la prostitución voluntariamente, junto con mujeres y adolescentes que han sido tratadas o lo están siendo, o coaccionadas para ejercer la prostitución, siendo explotadas sexualmente; y esto sucede a mujeres tanto nacionales como procedentes de otros países. Europa y los países industrializados tienen una potente industria del sexo que debe abastecerse con mujeres de todo tipo y es lo que origina una demanda importante de venta de servicios sexuales, pornografía o espectáculos eróticos. Esta oferta existe porque a la vez podemos hallar una importante demanda en términos cuantitativos y cualitativos. La mayoría de las personas que compran servicios sexuales son hombres, siendo escasísima la presencia de mujeres compradoras. Por tanto, son los hombres los que destinan parte de sus ingresos a pagar estos servicios por distintos motivos y circunstancias.

\section{Los jóvenes y los hombres son los que pagan por servicios sexuales}

Desde mi experiencia de recogida de información en los distintos contextos de prostitución, me he detenido en los procesos de iniciación masculina para comprar servicios sexuales. Muchos hombres comenzaron a pagar por sexo en su juventud y mientras que para unos es un evento puntual, para otros es asiduo. No solo es sexo lo que se compra, sino cariño, compañía y alguien que escuche. Dos eventos de iniciación son predominantes: las "despedidas de soltero" y el "fin de fiesta sin ligar". Jóvenes entre 18 y 30 años se han encontrado en más de una ocasión presionados por el grupo para acudir a un club de alterne, o algún espectáculo erótico (estriptís). Se trata de un rito de virilidad masculina, de demostración pública 
al grupo de iguales sobre su heterosexualidad. Si bien es cierto que la orientación sexual diferente a la heterosexualidad no es tan sancionada socialmente como en el pasado, todavía sigue siendo no tolerada en muchos contextos y no reconocida como una opción más. En estos eventos se espera que todos los participantes masculinos tengan un comportamiento similar. Para muchos de ellos ir a un club de alterne en grupo supone un aprendizaje sobre un tipo de relaciones afectivosexuales que hace dividir a las mujeres en dos grupos.

En España alrededor del 20\% de los hombres ha pagado por servicios sexuales alguna vez en su vida y algo menos los que lo hicieron en el último año. Sin embargo, estas estimaciones, procedentes de encuestas ${ }^{3}$, están subestimadas, porque no suele ser un comportamiento que se diga públicamente. Si bien es cierto que en el grupo de iguales toma un significado positivo, no lo es cuando se habla de ello en público o ante población general. Pero es indudable que la demanda es bastante mayor que la oferta, que se aumenta y se activa en momentos de crisis económica.

\section{Educar en las relaciones afectivo- sexuales}

Esta conducta de comerciar con el cuerpo, como puede ser la compraventa de servicios sexuales, genera debates ético-morales importantes que nos lleva a formarnos para educar a los adolescentes y jóvenes. Que sean solo los hombres los que pagan por servicios sexuales y sean mayoritariamente las mujeres las que venden su cuerpo, hace que la prostitución sea una cuestión de desigualdades de género que debe ser abordada desde la perspectiva de género y desde el proceso educativo para formar personas. Educar en la sexualidad, en las relaciones afectivo-sexuales, requiere una dedicación por parte de padres, educadores o

3 Véase el informe Apoyando a las víctimas de Trata http://www.violenciagenero.msssi.gob.es/violenciaEnCifras/estudios/investigaciones/2015/ pdf/Apoyando_Victimas_Trata.pdf

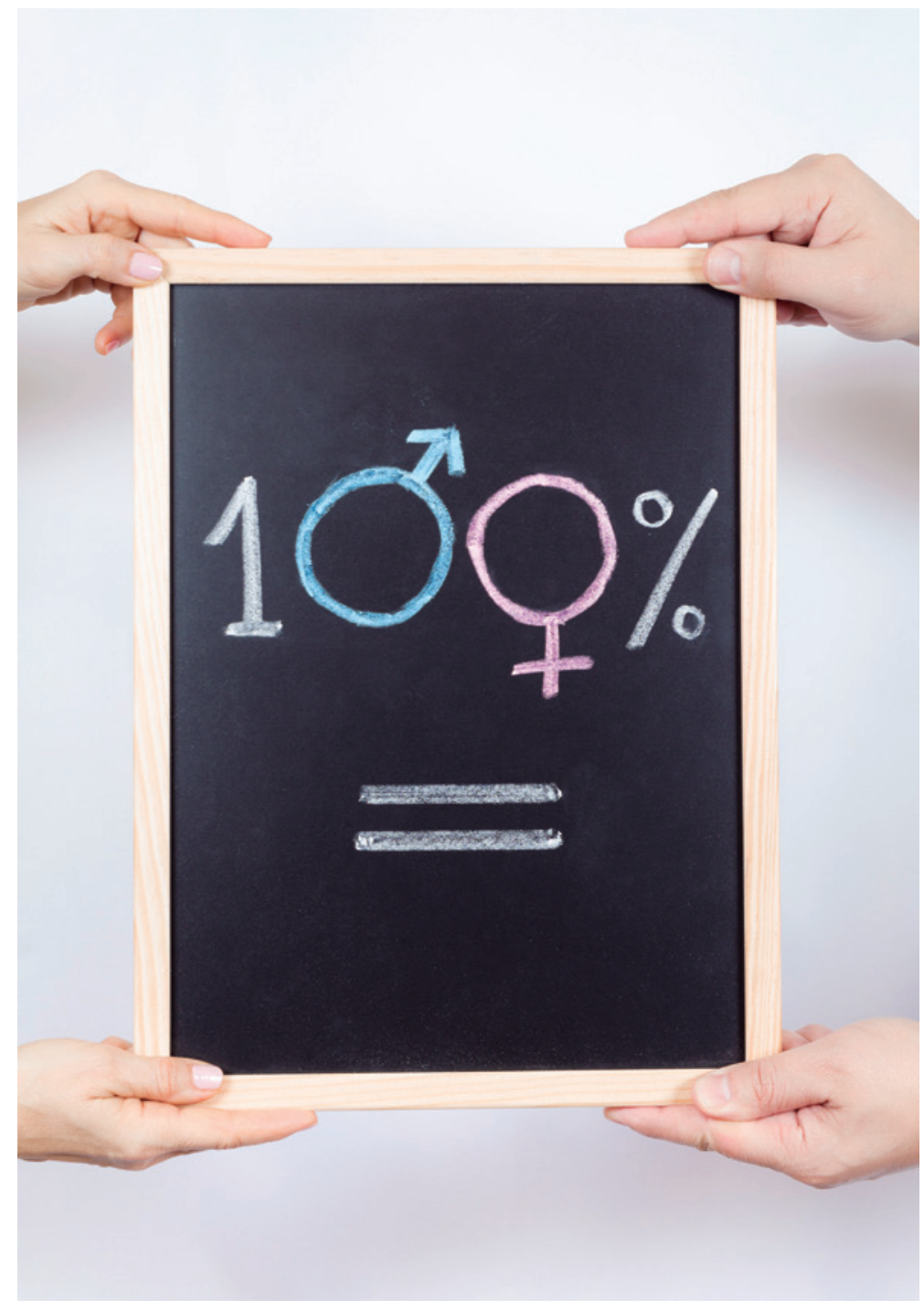

Que sean solo los hombres los que pagan por servicios sexuales y sean mayoritariamente las mujeres las que venden su cuerpo, hace que la proslitución sea una cuestión de desigualdades de género que debe ser abordada desde la perspectiva de género y desde el proceso educalivo para formar personas

profesores. A muchos de ellos no les resulta fácil abordar estos temas y los posponen. Sin embargo, las bases educativas sobre sexualidad y relaciones sexuales, explotación sexual y prostitución hay que asentarlas no cuando sean adultos, sino cuando todavía lo que dice su profesor o sus padres es importante para ellos. No hay recetas, pero me atrevería a sugerir tres indicaciones: 


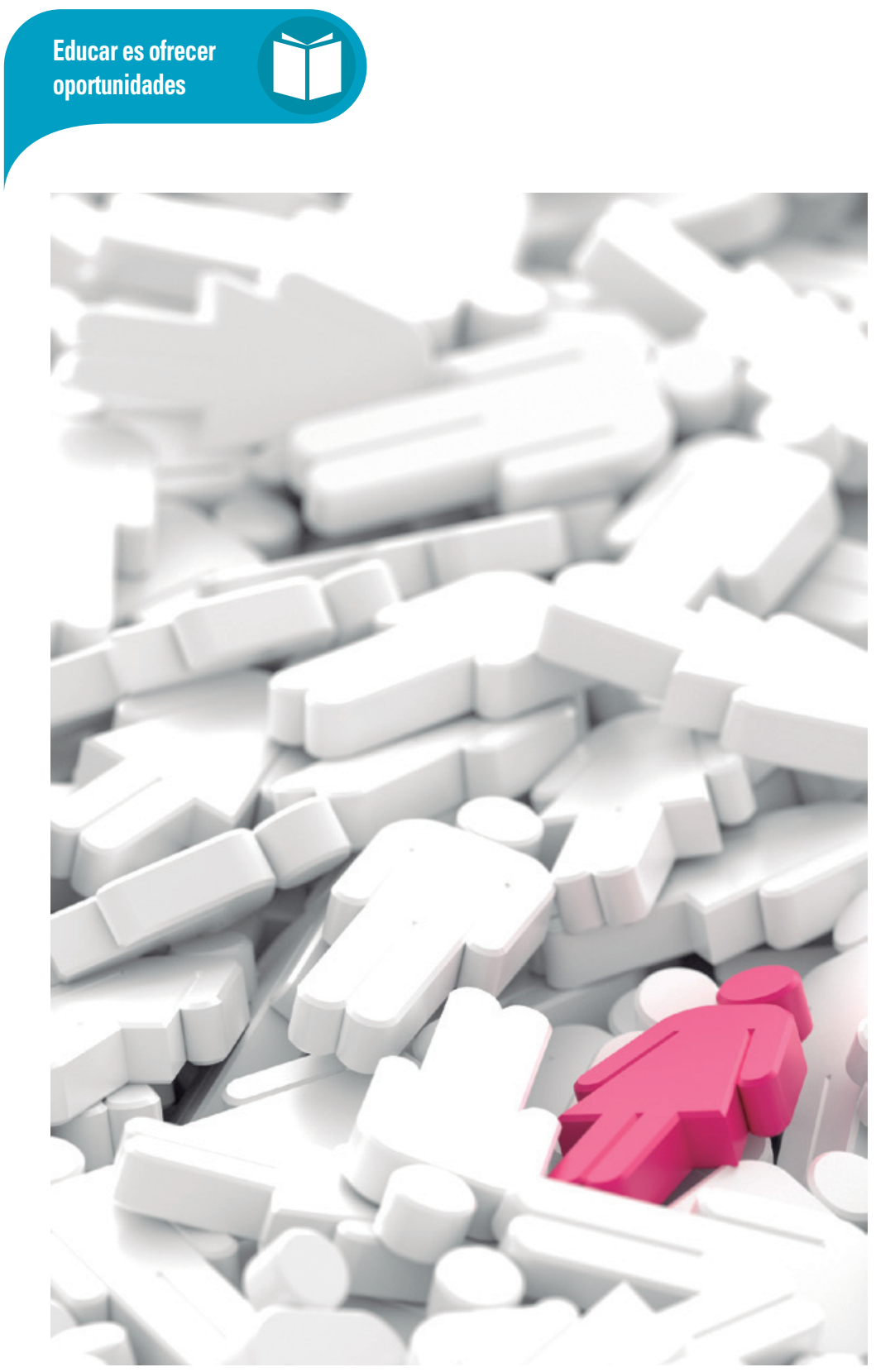

त Primero, abordarlo cuanto antes; indirectamente desde que surja la primera oportunidad durante toda la infancia y directamente al final de la educación primaria. Cuando comienza la adolescencia deben tener una formación básica con la que desenvolverse, pues posteriormente sus fuentes de información serán sus iguales, sin olvidar el "gran maestro" que será internet.

त Segundo, la información sexual deberá estar adaptada a su capacidad comprensiva y a lo que quiere saber. Un exceso de información es tan contrapreventivo como su escasez o ausencia. La necesidad de saber será satisfecha de alguna manera y si sus educadores no le proporcionan esa información la encontrarán en otro lugar, no siempre es la vía más aconsejable.

入 Tercero, la información debe ser preventiva y para ello debemos abandonar tanto el alarmismo como la excesiva tolerancia o minimización. Ser objetivos cuando hablamos sobre estos temas nos hace más creíbles. Ello no supone que los educadores no ofrezcan su propia valoración personal y la transmitan. Necesitan que generemos debates con ellos y ellas, para que puedan formar sus propias creencias, valores y posiciones.

Por último, los modelos afectivo-sexuales que los niños y adolescentes tengan a su alrededor serán los principales transmisores de valores y actitudes para sus conductas. Abordarlas desde el diálogo con ellos y ellas puede ser un buen ejercicio de aprendizaje y cercanía hacia ellos •

Meneses, C., Uroz, J., y RuA, A. (2017). "Flyers y anuncios de servicios sexuales en Madrid". Revista Latina de Comunicación Social, (72), 145-164. Recuperado de http://www.revistalatinacs. org/072paper/1158/RLCS-paper1158.pdf

Meneses, C., Uroz, J., Rua, A., Gortazar, C., y Castano, M. J. (2015). Apoyando a las víctimas de trata. Las necesidades de las mujeres víctimas de trata con fines de explotación sexual desde la perspectiva de las entidades especializadas y profesionales involucrados. Propuesta para la sensibilización contra la trata. Madrid: Delegación del Gobierno para la Violencia de Genero. Ministerio de Sanidad, Servicios Sociales e Igualdad. Recuperado de http://www. violenciagenero.msssi.gob.es/violenciaEnCifras/estudios/investigaciones/2015/pdf/Apoyando_Victimas_Trata.pdf 